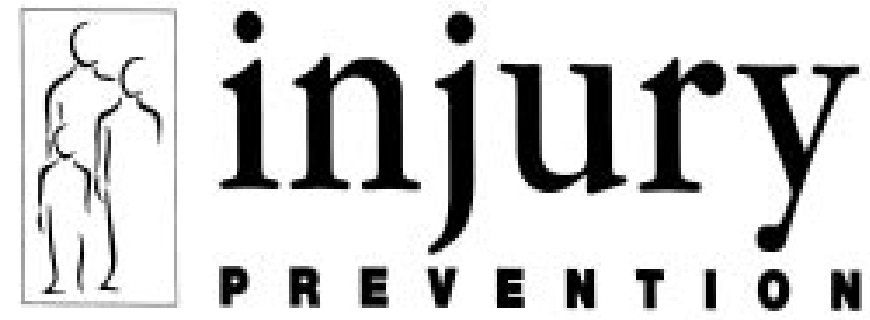

Journal of the International Society for Child and Adolescent Injury Prevention

\title{
Editorials
}

\section{Effective immediately Injury Prevention expands to all age groups}

For much of the past year, the editors have struggled trying to decide whether we should broaden the scope of the journal beyond children and adolescents. We have now elected to do so. Henceforth, effective immediately, our focus will include the prevention of injuries among adults as well as children. We also intend to publish more papers on safety promotion and the epidemiology of injury provided they have a direct bearing on prevention.

This decision was reached after much discussion and reflection. As a paediatrician, I was originally strongly biased toward retaining our original position. As a scientist, however, it is difficult to resist the conclusion that many of the most effective preventive measures, such as speed reduction, product safety, or smoke detectors, benefit everyone, not just children. Moreover, the results of research may be more applicable to other age groups than their authors may realize. From the outset we have received some excellent papers about adults that were hard to reject. Finally, from the perspective of advocacy, it has become

\section{Tasty books}

It is not often that editorial space is used to review books, but several recent publications seem so pertinent I could not resist. I realise that most readers have sufficient difficulty consuming all the journals they wish and that reading a book is far more time consuming. That is why reviews are important. I assure you these are worth the trouble.

Recommending books is, however, much like preparing a banquet. Few chefs intend that every dish be eaten to the last mouthful. Instead, they tempt us to savour bits here and there and hope that on another occasion, when we are hungrier or have more time, we will return to try some more.

In the case of the five books that prompted this departure from editorial custom, one is short enough to be digested at a single sitting; two are full course meals, and the last two, because they are so satisfying and easily digestible, deserve the ultimate commitment.

The first is actually a 40 page bulletin written by Ian $\mathrm{R}$ $\mathrm{H}$ Rocket entitled Injury and Violence: A Public Health Perspective. ${ }^{1}$ What makes it special is that a large and complex picture is portrayed well in so few pages. The book is increasingly clear that in most countries the child constituency is too small and too weak to influence policymaking the way a more inclusive approach could.

All things considered, this decision seems a sensible and perhaps somewhat overdue move. I view it as a sign of our maturation and hope most readers will agree. Some changes will be needed in the composition of the editorial board but there will be no lessening in our commitment to continue to produce a scientifically meritorious and informative, yet entertaining publication. The quality of this journal is reflected in the fact that it was accepted by the National Library of Medicine for inclusion in Index Medicus two years after it began publication.

Although our relationship with ISCAIP will remain unchanged, we would welcome the involvement of another, similar adult oriented or all age international organisation that might serve in the same capacity. Your suggestions and comments are most welcome.

clearly intended primarily for American readers, but the issues are viewed in an international context. And although much of the material is well known, a section addressing future directions identifies some emerging technologies like geographic information systems and the role of macroepidemiology.

One shortcoming is that the "public health perspective" touted in the title only addresses the mechanics of public health, not its spirit. There is scant evidence of the passion that has driven much of public health in the past. This is not a minor quibble. Surveillance systems are important, to be sure, but there is (or should be) much more to public health than collecting data. This branch of medicine has a distinguished tradition of focusing on policy and it is a discipline that is as committed to action as it is to furthering understanding. These elements are difficult to find in Rocket's otherwise admirable contribution. None the less, this is an excellent primer-well written, well illustrated, remarkably complete, and readily affordable.

The second is Reducing the Burden of Injury: Advancing Prevention and Treatment. ${ }^{2}$ In 1985, a Committee on 
Trauma Research published its landmark report Injury in America. Shortly after this the National Center for Injury Prevention and Control (NCIPC) was created-a centre with a mandate and funding that is a model in many respects, as well as a source of envy. The progress of NCIPC was reviewed two years later by another Institute of Medicine/National Research Council (IOM-NRC) sponsored committee whose report, Injury Control, appeared in 1988 .

About 10 years later the IOM decided to revisit the issue. A new expert committee on injury prevention and control was assembled, which, incidentally, included many members of the editorial board of this journal. The panel met frequently, held several open hearings, invited experts, and finally prepared this thoughtful and often provocative report. We owe a large debt of gratitude to the IOM and the foundations that funded these deliberations. Few other countries could afford the extensive input on which the report is based. And, like Injury in America, no one is expected to read this book from cover to cover, certainly not at a single sitting.

Reducing the Burden of Injury addresses many emerging issues in the field. Although, understandably, most are framed in the context of current social and political realities in the US, many of the recommendations pertain to all of us. Of the nine chapters three-Prevention Research, Case Studies on Prevention, and Challenges and Opportunitiesare the most widely applicable to other countries.

The tone of the document is generally authoritative, although it is perhaps a bit more diplomatic in some sections than I would have wished. To its credit, it takes on a number of tough issues. For example, on the contentious question of whether violence should continue to be part of the agenda, the committee concluded, unanimously, that it should. “ . . .. Despite important differences associated with intentionality, [we] strongly endorse the continued integration of all injury prevention activities within a common framework of research and program development" (ix). Other controversies, such as the struggle between regulation and freedom, are acknowledged repeatedly.

With respect to research, three promising areas are iden-

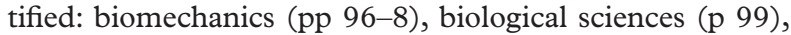
and behavioral sciences ( $\mathrm{pp}$ 99-101). In the latter, emphasis is placed on studying differences in risk perception, risk taking, and behavioral responses to safety improvements among different segments of the population. Without equivocation, the book affirms that injury is a public health problem (p 23) while stressing the vitally important role of other disciplines. It adds, however, that "proactive 'marketing' of public health is needed to arouse public awareness and concern, to counteract complacency or sluggishness, and to prod policy makers into action" (p 199).

Reminiscent of some of the points raised in a previous issue of the journal, the section on prevention research concludes with an interesting observation: "Surprisingly few researchers have explored empirically the operation of the market for safety, the effects of tort liability, and the effects of regulatory action .... Regarding the safety effects of tort liability, the authors add, "public health proponents typically assume that expansive liability rules are safety enhancing, whereas sceptics believe that the existing liability scheme tends to reduce safety by retarding innovation or inducing override behavior" (p 93).

Finally, with respect to an issue that affects everyone in this field, part of one table ( $\mathrm{p}$ 263) illustrates the lamentable expenditure for injury prevention research and training is presented in an unusual and illuminating way. The figures that follow are the amount of National Institutes of Health support (\$ millions) per years of potential life lost per 100000 population: AIDS 3.5, diabetes 1.9, cancer
1.6 , liver 1.2 , heart 0.7 , stroke 0.6 , lung 0.4 , pneumonia 0.5 , and injuries 0.1 ! This extraordinary distortion of values and priorities is not just seen in research, it applies equally to funding of prevention programs. *

A more formidable, but equally welcome, addition to any bookshelf of injury prevention books is that by Barss, Smith, Baker, and Mohan-Injury Prevention: An International Perspective. ${ }^{3}$ This encyclopaedic tour de force is reviewed in depth elsewhere in this issue ( $p$ 158). But let me add my two cents: alongside the earlier book by Mohan and Berger, this stands as the best researched, most genuinely international, and most comprehensive treatise on the subject. A copy has to be in every library and on the shelf of everyone in this field.

Next, and by no means least, is the splendid contribution by Simon Chapman, Over our Dead Bodies: Port Arthur and Australia's Fight for Gun Control. ${ }^{4}$ Don't be misled by the title. Although this is undoubtedly a book about gun control and situated squarely in the Australian social and political context, it has a wealth of valuable lessons for all injury control advocates, no matter where they live or what type of injury interests them.

The foremost of the lessons Chapman teaches us is how effective advocacy can be in the right hands and under the right circumstances. He begins by describing the massacre, and goes on to cover the case for fewer guns, the campaign for gun control, the main reforms that followed, the tactics of the gun lobby, and the responses he and his colleagues employed, concluding with a list of unfinished businessfuture tasks for gun control.

Apart from the gripping account of the central struggle, what make this book so compelling is Chapman's literary skills. He is unsurpassed in knowing how to make a difficult subject accessible. Many elements combine to make this is an attractive book: the cover, the liberal use of subheadings, the witticisms, cartoons, tables, graphs, and quotations. Above all there is Chapman's enviable writing style - an amazingly successful balance between the journalistic and scientific. This is also an expert's account of how to work with media and make the media work for you. Over our Dead Bodies is easy to read, compelling, colourful, consistently authoritative, and eloquently moving.

Although in many countries gun control is the dominant battleground on which public health advocates and citizens clash, the field of injury control is replete with parallels. Few preventive measures lack critics. They range from the "wind in the hair" opponents to helmet laws to those who insist that drunk drivers deserve more legal protection, not less. To combat such foolishness, consider carefully Chapman's advice: "Along with personalization-attaching a real person's experience to debate about issues-analogy and simile are probably the single most powerful rhetorical devices in public health advocacy".

My last recommendation is mostly just for pleasure. I recently read The Professor and the Madman. ${ }^{5}$ It was so captivating that I wanted to bring it to the attention of our readers but I needed an angle that would permit me to do so. I decided that the fact that it involves a senseless murder, and that the victim had seven children, was sufficient justification. There is, however, one other reason. This book is also about words and editors treasure words when they are used properly.

The Professor and the Madman describes the extraordinary relationship between Dr William Minor, an American surgeon during the civil war, and Dr Murray, the principal editor of the Oxford English Dictionary. It is a captivating story, elegantly told. If you are not intrigued by the account of Minor's madness, you should be by that of Murray's awesome talents and dedication. Minor was sentenced to a lifetime of incarceration in the Hospital for the Criminally 
Insane (the hospital from which the term "bedlam" originates). For more than 30 years he made extensive contributions to the dictionary. It was only some while after he began submitting these contributions that his situation was discovered in spite of the fact that Minor and Murray lived less than 30 miles apart. The story is compelling. The style is captivating. The line cuts are beautiful. Read it and enjoy!

*In case Americans feel picked on, Canada's recent budget announcement included over $\$ 50$ million earmarked for diabetes and not one penny specifically for injuries!

\section{Close to home}

Joseph Stalin is reputed to have said or written: a million deaths is a statistic; a single death is a tragedy. Some survey results show that even parents who accept that injuries are preventable, none the less believe injuries will not happen to their children. If this is generally true, we may need to put more emphasis on publicising individual events-what in medical terms is referred to as "case reports", or, in Chapman's terms, "personalizing". So, to bring the statistics close to home, and at the risk of being pronounced guilty of a sin against which I have preached, that of "parochialism", I include in this issue three such examples, all Canadian.

The first is the account by Claire Adamson describing how her daughter lost her hand on an escalator. It is a tragic story and one that illustrates all too well how poorly designed and badly maintained equipment can maim for life. To the credit of parents and child, the case was taken to court and after a long ordeal the child received a substantial sum "in compensation". Of course, no sum of money can compensate such an injury; but perhaps it helps to know that by taking legal action others may be spared similar calamities.

The second is a description by a distinguished Canadian colleague, Roger Tonkin, an international leader in adolescent medicine. Tonkin frequently contributes to the Medical Post a well written column about youth he has treated. I asked if he would share one pertaining to injuries. I trust readers will agree that his account of the aftermath of an all too common car crash rings true for all of us. Whether it is truly a story with a happy ending, I leave for you to decide.

Finally, there is the poignant letter from another colleague, Marielle Olivier. When I learned that her sister
1. Rockett IRH. Injury and violence: a public health perspective. Population Bulletin 1998;53(4) (40 pages). ISBN 0032-468X.

2 Bonnie RJ, Fulco CE, Liverman CT, eds. Reducing the burden of injury: advancing prevention and treatment. Washington, DC: National Academy Press, 1999 (303 pages, including index) ISBN 0-309-06566-6.

3 Barss P, Smith G, Baker S, et al. Injury prevention: an international perspective —epidemiology, surveillance, and policy. New York: Oxford University Press, 1998 ( 375 pages, including index). ISBN 0-19-511982-79.

4 Chapman S. Over our dead bodies: Port Arthur and Australia's fight for gun control. Annandale, Australia: Pluto Press, 1998 (\$A 24.95; 298 pages, including index). ISBN 1-86403-037-2.

5 Winchester S. The professor and the madman; a tale of murder, insanity, and the making of Oxford English dictionary. New York: Harper Collins $(\$ 22.80 ; 242$ pages). ISBN 0-0601-7596-6.

had been killed in a "car accident" I wrote to express my sympathies and asked what actually happened. Although the victim was not a child or adolescent, I make no apologies for publishing her reply. The drunken driver problem affects all age groups. Every injury prevention expert knows that alcohol is a major risk factor, not just for drivers, but in almost every injury producing situation. The seriousness cannot be underestimated, yet those who drink to excess and those who permit them to do so-friends, relatives, or bartenders - are rarely punished sufficiently to deter others. This must change and we must help it change. For starters, I have asked colleagues in Canada to join forces with Mothers Against Drunk Driving (MADD) to help have more stringent federal legislation passed.

Apart from recounting this personal tragedy, MADD sent some statistics so mind boggling that I wanted to share them in the hope that someone can explain them. In Canada, in 1997, 1680 people were killed and 74000 injured in alcohol related crashes and I estimate that perhaps half were drivers. Nevertheless, the previous year there were only 133 charges for impaired driving causing death and 1028 charges for bodily harm! Even more perplexing is that in Ontario, the largest province, conviction rates were $43 \%$ and $48 \%$, respectively and I assume this reflects the national average. Help me understand how this can be? Is it the same everywhere?

I B PLESS Editor

\section{A brief introduction to new board members}

Changing our policy to include injuries in all age groups made it necessary to add new board members. To make this possible, it was necessary for some to leave. The list of departures includes mainly those who have served faithfully since the outset, to whom we are tremendously grateful. New members were selected to ensure that we could deal competently with a broader range of prevention issues, especially those affecting adults. The main areas of expertise represented by the newcomers are shown below. More detailed profiles will appear in subsequent issues.

Colin Cryer: statistician; elderly

Lois Fingerhut: epidemiologist; coding and surveillance

Stig Håkansson: economist; product safety

Olive Kobusingye: trauma surgeon

Jess Kraus: epidemiologist; head injuries

John Langley: epidemiologist; varied

Tom Leamon: ergonomics; Liberty Mutual Insurance Peter Lundqvist: agricultural and occupational health
Ellen Mackenzie: epidemiologist; cost of injury

Lenora Olson: anthropologist; emergency medical services

Leon Robertson: epidemiologist; methodology

Roy Shephard: physiologist; sports safety

Gordon Smith: epidemiologist; varied

Allan Williams: psychologist; traffic safety

Bill Yule: psychologist; post-traumatic stress 